\title{
INDUSTRIAL RESEARCH ASSOCIATIONS IN BRITAIN
}

"R ESEARCH for Industry, 1958", which reports on work done by the industrial research associations in the Government scheme, this year adopts a new pattern which has much to commend it. It includes the report of the Industrial Grants Committee of the Council for Scientific and Industrial Research which comprises a review of grant policy during 1957-64 (see p. 211 of this issue), and a review of the achievements during the past five years of the ten research associations to which new or revised terms of grant were recommended during the year. Apart from brief notes on any outstanding features of the work of other research associations during the period, the bulk of the report comprises a list of existing associations, giving their officers, total income and publications during the year and a brief note on the scope of the present work of each association. There is also an assessment by Dr. D. T. A. Townend of the place of the research associations in the evolution of scientific endeavour, and a report entitled "New Ideas, New Products, Now Processes" on how cooperation research serves the textile industries. In this report, which covers the work of several researeh associations, the point is made that one-fifth of an association's resources is only adequate for fundamental research if the total resources are big enough.

Of the research associations which received new or revised terms of grant during the year, stress is laid on the basic research into the composition of gelatin and glue, the structure of the gelatin molecule, the properties of solutions and gels and the conversion of collagen into gelatin being carried out by the British Gelatine and Glue Research Association; the economic value of the work of the British Hat and Allied Felt Makers' Research Association; the achievements of the British Hydromechanics Research Association in the design and utilization of pumps and in high-pressure hydraulic machinery and in hydraulic model testing. The Furniture Development
Council has conducted a basic investigation into factors affecting the strength and rigidity of cabinet construction, developed test methods for furniture lacquers and worked on a new, economical materialwood chipboard. The Heating and Ventilating Research Council began its first major research project in 1956-57-an investigation of problems arising from the intermittent heating of buildings, with the view of ascertaining possible fuel savings by choosing in advance equipment and programme of the daily heating cycle in relation to the thermal characteristics of the building and installation. The Lace Research Association has carried out much work on new types of yarn and on problems arising in dyeing and dressing synthetic fibre materials, and is engaged in a basic study of the bobbin and carriage, which is the central feature of major types of lace machines.

Basic research carried out by the British FlourMillers' Research Association includes a complete analysis of the amino-acid composition of flour and of the changes which occur when it is made into bread. The Research Association of British Rubber Manufacturers has extended its cover to plastics, notably polyvinyl chloride and polyethylene, and has been investigating the basic physical characteristics of rubber and plastics and the influence of service conditions such as temperature on these characteristics. An outstanding piece of chemical research increased knowledge of how traces of certain metals, notably copper and manganese, can cause premature deterioration of important classes of rubber products, especially rubber-proofed fabrics. The British Coke Research Association has developed instruments such as an isothermal bomb calorimeter for accurate determination of the calorific value of solid and liquid fuels and an electromagnetic semimicrobalance for use in fundamental studies relating to carbon.

\section{AGRICULTURAL RESEARCH IN BRITAIN}

\begin{abstract}
A CORRESPONDENT, commenting in a Scottish farming paper on the Report of the Agricultural Research Council for 1957-58, complained that he could find no reference to research on grass tetany. Because of its current seriousness, he felt that some of the four million pounds that the Council administers should be allocated directly towards research into this problem. If he had read the report with deeper understanding he would have realized that such a criticism was not really justified. For example, at the Rowett Research Institute there are in progress fundamental studies on the physiology of rumen digestion with particular reference to young grass which is high in potash and nitrogen. The work is not labelled grass tetany or hypomagneszmia, but it is in fact just the sort of work that will lead to a better understanding of the metabolic diseases of livestock which are still very largely unsolved. Agricultural research has long since passed from its old phase of an empirical approach to outatanding problems, and this is well illustrated by this report,
\end{abstract}

for the main emphasis is on fundamental studies necessary for a better understanding of the vital mechanisms of plants and animals.

Another illustration of this approach is provided by the investigations, mainly at Rothamsted Experimental Station and at the University of Durham, into the biology of the potato root eelworm. Studies have been made of diffusate from potato roots which stimulates hatching of the cysts, and investigations are proceeding at several centres into the chemistry of this material, with the view of obtaining a means of causing hatching in the absence of the host plant.

A feature of the report is the very considerable emphasis which is given to the several aspects of poultry research, which for a number of years was something of a Cinderella so far as the Council was concerned. The industry, with an annual output of $£ 200$ millions, is second in importance in Britain to dairying, and it also is one of the most heavily sub. sidized. It is very important that the industry 
should be more efficient, and especially is this true in respect of disease control, for wastage is a very heavy source of loss. To-day there are two poultry research institutes, one wholly and the other partly financed by the Council, while there is a considerable amount of poultry research being supported at other centres. One pleasing aspect of the breeding work is the attention that is being given to methods which will be within the compass of the small breeder, who is in imminent danger of being squeezed out by the large organizations producing hybrid chicks.

Possibly the most notable advance from the point of view of the farmer relates to the control of husk in cattle, which is caused by the lungworm, Dictyocaulus viviparus. This work has been undertaken by the University of Glasgow Veterinary School and was started in 1952. The successful outcome of this work is that double vaceination, using doses of larvæ that have been partially inactivated by irradiation with $\mathrm{X}$-rays, gives an effective field control of a disease which has been a serious source of loss to farmers. The cost to the cattle industry has not been confined to deaths and loss of thrift, but has included also the cost of housing and hand-feeding susceptible animals in order to avoid infection. Now that farmers have an effective control of the disease, it will be possible for them to put calves out to pasture and thereby considerably lower the cost of rearing. X-irradiation opens up enormous possibilities in the control of other endo-parasitic infections, and further work is proceeding on this side.

One final point about the Council's activities-. though the greater part of its funds go to research institutes such as Rothamsted Experimental Station and the National Institute for Research in Dairying, the universities are by no means neglected. Apart from a number of research units, there were ninety-four separate projects at sixteen universities which were receiving grants in March 1958. It seems that fears expressed a few years ago that the big institutes would monopolize research in agriculture, and the sciences basic to agriculture, are groundless, for it is obviously the Council's policy to encourage workers at the universities, who have, among their other duties, the task of training research workers to staff the institutes.

\section{SELF-REGULATION IN LIVING SYSTEMS}

$\mathrm{T}$ HE first Ottawa symposium on self-regulation in living systems, held in October 1958 (see Nature, 183,730 ; 1959), led to requests for a second meeting with particular emphasis on problems of stability in self-regulating systems. This meeting was held at the National Research Council laboratories in Ottawa on March 11. As on the previous occasion, a very wide range of professions was represented, and the attempt was made to inerease our understanding of the behaviour of living systems by analogy with known physical and mathematical techniques and concepts.

The opening paper, outlining the nature of the problem, was by a physiologist, Dr. A. S. V. Burgen (MeGill University, Montreal). Burgen emphasized that all physiological problems are multifactorial in character, and that in a real biological system it is impossible to isolate a single variable. A real need exists for more adequate mathematical techniques to deal with such problems. However, at present, simplifying assumptions are essential in order to reduce problems to manageable form. Thus we may, for example, consider the blood circulatory system as raade up of two pumps-namely, the right and left ventricles of the heart-connected in series with each other and with the blood vessels of the body. The problem here is how the outputs of the two pumps are maintained equal to one another. It is found that over a wide range of input pressures the output flow is proportional to this pressure, and in this way automatic regulation is achieved. It appears that blood pressure is controlled by sensors acting via the base of the brain to cause dilation or contraction of capillaries in the circulatory system. In these cases, and, for example, in the problem of maintenance of body temperature, the mechanisms by which the actual operating values are determined remain largely unknown at present. It was also pointed out that there are definite time-cycles within the body for which at present no explanations have been given. Following Burgen's paper there was considerable discussion as to whether the dependence on temperature of the rate of chemical processes might provide an adequate mechanism for the maintenance of an internal temperature standard.

Dr. A. C. Smith (Computing Centre, University of Ottawa) presented some analysis of the properties of idealized control systems, using the method of the Laplace transformation. The analysis, however, was limited to strictly linear systems, and it was felt that the non-linear problem is in fact of great importance to physiologists and others. The conclusion reached in the analysis was that optimum control conditions obtain when the control action depends upon both the variable under control and its time derivative. This conclusion agreed with the general experimental observations of the physiologists present. In the discussion the influence of time delay or phase of negative feedback on the stability of systems was of primary interest. Physiological systems diseussed in this connexion included problems of neurological instability and the recent work, reported in the literature, on the relation between stammering and delays in the reception of aural signals. The galvanometer amplifier using a light beam and photocell to provide a high degree of negative feedback offers a simple mechanical system showing some of the important features. If the time delay in the response of the cell is appreciable, the galvanometer amplifier system may 'build up' to a state of oscillatory instability. It should be emphasized that the polarity of the feedback is still nominally negative; if the feedback is connected up in the opposite sense (positive feedback) then the galvanometer amplifier becomes entirely unstable, and obviously so!

An outline of some modes of operation of digital computers by Dr. Bradford Dunham (Research Laboratory, International Business Machines, Poughkeepsie, New York) opened the way for analogies to be drawn with living systems. In programming a computer a specific problem must be given a precise mathematical formulation and then translated into machine language. Under these conditions we may 